\title{
Donor Site Repair
}

David J. Smith, Jr., MD, Ann Arbor, Michigan, Philip D. Thomson, Ph.D., St. Louis, Missouri, Warren L. Garner, MD, Jorge L. Rodriguez, MD, Ann Arbor, Michigan

\begin{abstract}
Delayed healing of skin donor sites may be costly and life threatening, especially in patients with large body-surface area burns. A donor site dressing should muximize the ability of the wound to heal without increasing the risk of local infection, systemic infection, or both. Specifically, the possibility of a secondary infection may either slow the healing process or ultimately convert the donor site to a full-thickness wound. A number of materials, ranging from gauze to biological agents, have been investigated for use as donor site dressings. The use of hydrocolloids for donor sites has been studied extensively, and, compared with conventional dressings, improved healing rates are reported. Our recent study using a hydrocolloid dressing confirmed earlier research showing fewer infections and more rapid donor site healing.
\end{abstract}

From the Department of Surgery, University of Michigan Medical Center, Ann Arbor, Michigan (D.J.S., W.L.G., J.L.R.); the Technology Planning Division, Mallinckrodt Medical, Inc., St. Louis, Missouri (P.D.T.)

David J. Smith, Jr., MD, and Philip D. Thomson, PhD, acknowledge support in part for research and travel from ConvaTec.

Requests for reprints should be addressed to: David J. Smith, Jr., MD, Plastic and Reconstructive Surgery, University of Michigan Medical Center, 2130 Taubman Center, 1500 E. Medical Center Drive, Ann Arbor, Michigan 48109-0340.
The importance of rapid healing in skin graft donor 1 sites is emphasized by the increasing number of methods designed to achieve earlier reepithelialization [1]; however, other unique concerns are associated with the skin graft donor site. In large burns, improved healing may allow for faster reharvesting, whereas in smaller injuries, hastened epithelialization may result in less scarring. Conversely, a secondary infection may either slow the healing process or ultimately convert a partial skin-thickness donor site to a full skin-thickness loss [2]. Thus, size of the donor site, site selection [3], skin preparation, graft depth, hemostasis [4], and choice of dressing become important considerations. All of these issues have a role in the ultimate healing of a skin graft donor site and in the incidence of infection.

\section{DONOR SITE HEALING AND BACTERIA}

Where healthy tissue exists and bacterial populations are noninvasive, wound healing proceeds in a normal fashion [5-7]. In these cases, bacterial populations may stimulate the inflammatory response that initiates wound healing [8-9]. Histologically observed invasion of viable tissue by pathogenic organisms distinguishes invasive wound sepsis from colonization [6]. Noninvasive bacterial populations may remain over the surface of the wound without impairing healing below [5]. The critical factor in wound healing appears to be the bacterial population in the wound, as opposed to the population over the surface of the wound.

Bacterial populations vary over different parts of the body [10]. This fact, plus concern for final cosmetic result, may influence donor site selection [3]. Preparation of the donor site area before harvest, as well as careful attention to hemostasis and clot removal from the bed after harvest, may be important for the control of microbial populations [4]. Depth of the donor area not only affects scar formation, but may also have a role in the incidence of infection [3]. As the depth of the wound increases, healing is slowed, and the wound becomes more susceptible to bacterial contamination as the time to healing is prolonged. When colonization of the wound occurs, there may be enhancement of the initial inflammatory response caused by skin harvest. If this inflammatory response persists, the ensuing pathologic finding of edema and mediator-induced necrosis may predispose the underlying tissue to invasion.

Early after harvest, the inflammatory response in the surrounding tissue may mask the inflammatory response associated with bacterial colonization. Hunt [11] showed the cascade of inflammatory events associated with normal wound healing; however, the inflammatory response compounded by microorganisms may be severe and lead to destruction of adjacent tissue [12]. Necrosis of tissue assists microbial invasion and conversion of the 


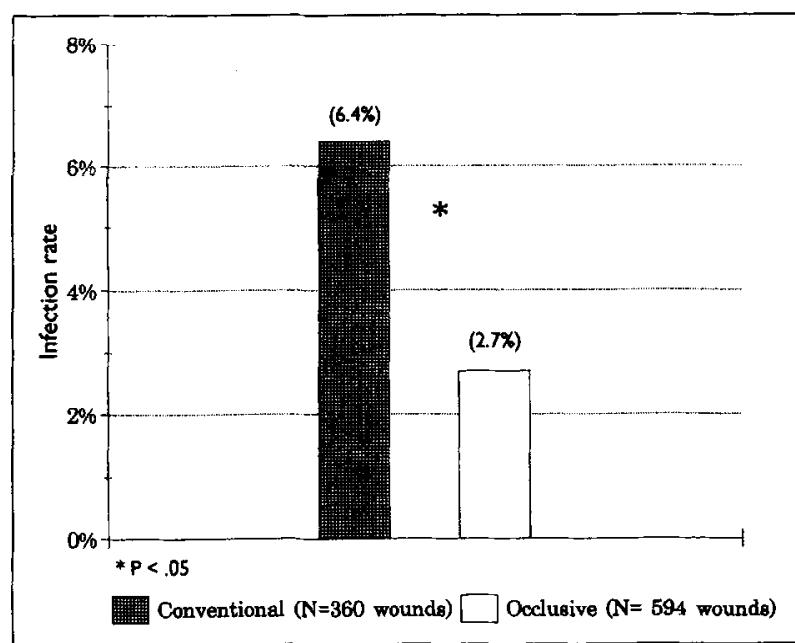

Figure 1. Infection rates for donor sites dressed with a conven tional or occlusive dressing. (Adapted with permission from [19].)

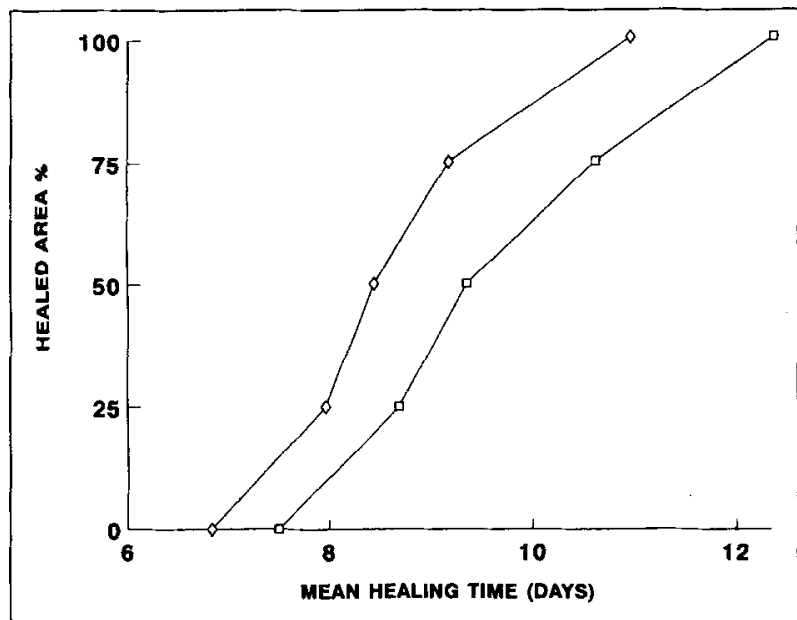

Figure 2. Mean healing time, paired donor sites in 12 patients treated with silver sulfadiazine cream alone (D) or silver sulfadiazine cream containing epidermal growth factor $(\diamond)$. (Reprinted with permission from [23].)

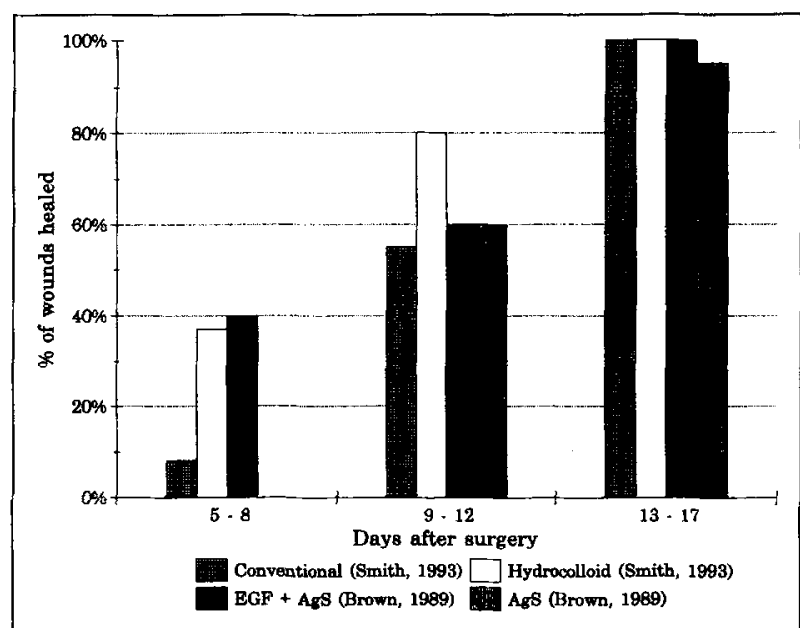

Figure 3. Reported time to healing skin graft donor sites. From $[2,23]$. skin graft donor site to a full skin-thickness injury with a reported incidence of infection as high as $25 \%[2,13,14]$.

\section{DONOR SITE DRESSINGS AND INFECTION}

A donor site dressing should maximize the ability of the wound to heal without increasing the risk of local or systemic infection. Donor site dressings are divided into several categories: open, semi-open, semi-occlusive, and occlusive. As early as 1962, Winter [15] showed that moist wounds healed faster than wounds left to dry out. This observation has led the care of skin graft donor sites away from the conventional dry gauze dressings toward the semi-occlusive or occlusive dressings. Although these occlusive dressings provide moist environments for wound healing, there has been concern that occlusion of wounds would lead to increased infection [16-18]. However, Hutchinson and McGuckin [19], in a review of 29 donor site studies, showed an infection rate of only $2.7 \%$ in 594 occluded wounds versus an infection rate of $6.4 \%$ in 360 conventionally dressed wounds (Figure 1). In a recent study on donor site wound healing, 30 burn patients with skin graft donor sites were randomized to receive either an occlusive (DuoDERM CGF; ConvaTec, Skillman, NJ) or conventional gauze dressing on their wounds [2]. Wounds in both groups were colonized with bacteria; however, only conventionally dressed wounds became infected (Table I). Bacteria were present intraoperatively in 9 of $14(64 \%)$ hydrocolloidtreated sites and in 5 of $16(31 \%)$ conventionally treated sites. At the first dressing change, positive cultures were obtained from 4 of $12(33 \%)$ of the hydrocolloid dressed wounds and from 6 of $7(86 \%)$ of the conventionally dressed wounds. Infection was determined by organism recovered and by the established classic clinical signs [20]. The conventionally dressed wounds had a $25 \%$ infection rate caused by Staphylococcus, Pseudomonas, and Candida. In this patient population, colonization of the wound under the hydrocolloid dressing did not lead to infection.

\section{DONOR SITE HEALING AND THE WOUND ENVIRONMENT}

Hydrocolloid dressings provide a unique wound healing environment for the epithelialization of skin graft donor sites while decreasing the rate of wound infection. Normal wound healing is a series of orchestrateu events with an initiation phase, collagen deposition phase, keratinocyte ingrowth phase, and maturation phase. The process is dependent on oxygen delivery to tissue, $\mathrm{pH}$ of tissue, and development of a local wound environment conducive to the cells involved in repair. Growth factors provided exogenously or by repairing cells have been the focal point of numerous wound healing investigations $[2]-23]$. Brown and associates [23] investigated epidermal growth factor (EGF) in association with skin graft donor site healing. This work showed that EGF decreased the time to healing to 7-17 days (mean: 10.9 days) compared with 9-21 days (mean: 12.3 days) for control donor sites (Figure 2). 


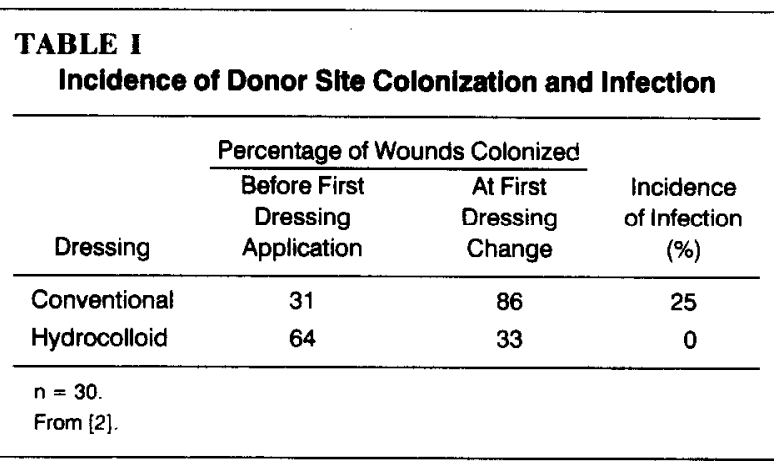

Although the mechanism of wound healing promotion by hydrocolloids is unknown, Madden et al [14] showed that exudates from wounds occluded with a hydrocolloid dressing promoted keratinocyte proliferation. When the results of Smith et al [2] are compared with those of Brown et al [23], it appears that both the hydrocolloid dressing studied and EGF support the early stages of wound healing in a similar fashion (Figure 3). However, in the mid-stage of reepithelialization, the hydrocolloid dressing appeared superior to both EGF and control treatment. These data suggest that hydrocolloids provide a similar rate of wound healing to that of EGF. This comparison of data is based on the assumption that the donor sites in the two studies were of similar size and depth.

In summary, the search for an ideal donor site dressing continues. Improvements in healing and infection rates remain important considerations. Currently, some hydrocolloid dressings appear to possess many of the benefits for the designation of the ideal donor site dressing.

\section{REFERENCES}

1. Feldman DL. Which dressing for split-thickness skin graft donor sites? Ann Plast Surg 1991; 27: 288.

2. Smith DJ, Thomson PD, Bolton LL, Hutchinson JJ. Microbiology and healing of the occluded skin-graft donor site. Plast Reconst Surg 1993; 91: 1094-7.

3. Greenhalgh DG, Barthel PP, Warden GD. Comparison of back versus thigh donor sites in pediatric patients with burns. J Burn Care Rehabil 1993; 14: 21-5.

1. Prasad JK, Feller I, Thomson PD. $\Lambda$ prospective controlled trial of Biobrane vs scarlet red in skin graft donor areas. J Burn Care Rehabil 1987; 8: 384-6.

5. Robson MC, Lea CE, Dalton JB, Heggers JP. Quantitative bacteriology and delayed wound closure. Surg Forum 1968; 19: 501-2.

6. Teplitz C, Davis D, Mason AD, Moncrief JA. Pseudomonas burn wound sepsis. I. Pathogenesis of experimental burn wound sepsis. J Surg Res 1964; 4: 200-16.

7. Eriksson G, Eklund AE, Kallings LO. The clinical significance of bacterial growth in venous leg ulcers. Scand J Infect Dis 1984; 16: $175-80$

8. Tenorio A, Jindrak $\mathrm{K}$, Weiner $\mathrm{M}$, et al. Accelerated healing in infected wounds. Surg Gynecol Obstet 1976; 142: 537-43.

9. Kan Gruber D, Gruber C, Seifter E, et al. Acceleration of wound healing by Staphylococcus aureus. Surg Forum 1981; 32: 76-8.

10. Aly R. Skin microbiology and occlusion. In: Alexander JW, Thomson PD, Hutchinson JJ, eds. International Forum on Wound Microbiology. Princeton, NJ: Excerpta Medica, 1990: 1-5.
11. Hunt TK. Basic principles of wound healing. J Trauma 1990; 30: $\mathrm{S} 122$.

12. Fantone JC, Ward PA. Role of oxygen-derived free radicals and metabolites in leukocyte-dependent inflammatory reactions Am J Pathol 1983; 107: 397 .

13. Griswold JA, Grube BJ, Engrav LH, et al. Determinants of donor site infection in small burn grafts. J Burn Care Rehabil 1989; 10: 531-5.

14. Madden MR, Nolan E, Finkelstein JL, et al. Comparison of an occlusive and semiocclusive dressing and effect of the wound exudate upon keratinocyte proliferation. J Trauma 1989; 29: 924.

15. Winter GD. Formation of the scab and the rate of epithelialization of superficial wounds in the skin of the young domestic pig. Nature 1962; 193: 293-4.

16. Laforet EG. Wound dressing or window dressing? Arch Surg 1974; 109: 457.

17. Evans AJ. Treatment of burns today. Proc R Soc Med 1971; 64: 21-2.

18. Bennett RG. The debatable benefit of occlusive dressings for wounds. Dermatol Surg Oncol 1982; 8: 166-7.

19. Hutchinson JJ, McGuckin M. Occlusive dressings: a microbiologic and clinical review. Am J Infect Contr 1990; 18: 257-68.

20. Altemeier W, Burkerts F, Pruitt B, Sandusky W. Manual on Control of Infection in Surgical Patients, 2nd ed. Philadelphia: JB Lippincott Company, 1976: 29-30.

21. Brown GL, Curtsinger LJ, White M, et al. Enhancement of epidermal regeneration of biosynthetic epidermal growth factor. $\mathbf{J}$ Exp Med 1986; 163: 1319-24.

22. Nanney LB. Epidermal growth factor-induced effects on wound healing. [Abstr.] Clin Res 1987; 35: 706A.

23. Brown GL, Nanney LB, Griffen J, et al. Enhancement of wound healing by topical treatment with epidermal growth factor. N Engl J Med 1989; 321: 76-9.

\section{DISCUSSION}

M. Kerstein: Do you have any problem with unwanted dressing adherence?

D. Smith: Yes, they are not always easy to keep on the lower back or buttocks or on circumferential donor sites. For the latter, I cannot recommend the hydrocolloid because I do not know how to keep it there. For those, I use a semi-occlusive dressing, fine mesh gauze, or silver sulfadiazine. A dry dressing, whether it is parachute silk or just plain gauze, is probably the worst way to heal a wound.

C. Burton: Would you agree that occlusion is the right thing for donor sites?

D. Smith: Yes, based on these criteria: less pain, faster healing, less infection, and simple patient acceptance.

C. Burton: What is the time between dressing changes?

D. Smith: From 2-5 days.

M. Kerstein: What is the normal infection rate for donor sites?

D. Smith: The local infection rate, not for systemic infections, reported for conventionally dressed donor sites is $5-25 \%$. 